\title{
Complete genome sequence of Brachyspira murdochii type strain $\left(56-150^{\top}\right)$
}

\author{
Amrita Pati ${ }^{1}$, Johannes Sikorski ${ }^{2}$, Sabine Gronow ${ }^{2}$, Christine Munk ${ }^{3}$, Alla Lapidus ${ }^{1}$, Alex \\ Copeland ${ }^{1}$, Tijana Glavina Del Tio ${ }^{1}$, Matt Nolan' ${ }^{1}$, Susan Lucas ${ }^{1}$, Feng Chen ${ }^{1}$, Hope Tice ${ }^{1}$, \\ Jan-Fang Cheng ${ }^{1}$, Cliff Han ${ }^{1,3}$, John C. Detter ${ }^{1,3}$, David Bruce ${ }^{1,3}$, Roxanne Tapia ${ }^{3}$, Lynne \\ Goodwin $^{1,3}$, Sam Pitluck ${ }^{1}$, Konstantinos Liolios ${ }^{1}$, Natalia Ivanova ${ }^{1}$, Konstantinos \\ Mavromatis ${ }^{1}$, Natalia Mikhailova ${ }^{1}$, Amy Chen ${ }^{4}$, Krishna Palaniappan ${ }^{4}$, Miriam Land ${ }^{1,5}$, Loren \\ Hauser $^{1,5}$, Yun-Juan Chang ${ }^{1,5}$, Cynthia D. Jeffries ${ }^{1,5}$, Stefan Spring ${ }^{2}$, Manfred Rohde ${ }^{6}$, Markus \\ Göker $^{2}$, James Bristow ${ }^{1}$, Jonathan A. Eisen ${ }^{1,7}$, Victor Markowitz ${ }^{4}$, Philip Hugenholtz ${ }^{1}$, Nikos \\ C. Kyrpides ${ }^{1}$, and Hans-Peter Klenk ${ }^{2 *}$ \\ ${ }^{1}$ DOE Joint Genome Institute, Walnut Creek, California, USA \\ ${ }^{2}$ DSMZ - German Collection of Microorganisms and Cell Cultures GmbH, Braunschweig, \\ Germany \\ ${ }^{3}$ Los Alamos National Laboratory, Bioscience Division, Los Alamos, New Mexico, USA \\ ${ }^{4}$ Biological Data Management and Technology Center, Lawrence Berkeley National \\ Laboratory, Berkeley, California, USA \\ ${ }^{5}$ Oak Ridge National Laboratory, Oak Ridge, Tennessee, USA \\ ${ }^{6} \mathrm{HZI}$ - Helmholtz Centre for Infection Research, Braunschweig, Germany \\ ${ }^{7}$ University of California Davis Genome Center, Davis, California, USA \\ ${ }^{*}$ Corresponding author: Hans-Peter Klenk
}

Keywords: host-associated, non-pathogenic, motile, anaerobic, Gram-negative, Brachyspiraceae, Spirochaetes, GEBA

\begin{abstract}
Brachyspira murdochii Stanton et al. 1992 is a non-pathogenic host-associated spirochete of the family Brachyspiraceae. Initially isolated from the intestinal content of a healthy swine, the 'group B spirochaetes' were first described under as Serpulina murdochii. Members of the family Brachyspiraceae are of great phylogenetic interest because of the extremely isolated location of this family within the phylum 'Spirochaetes'. Here we describe the features of this organism, together with the complete genome sequence and annotation. This is the first completed genome sequence of a type strain of a member of the family Brachyspiraceae and only the second genome sequence from a member of the genus Brachyspira. The 3,241,804 bp long genome with its 2,893 protein-coding and 40 RNA genes is a part of the Genomic Encyclopedia of Bacteria and Archaea project.
\end{abstract}

\section{Introduction}

Strain 56-150 ${ }^{\mathrm{T}}$ (= DSM $12563=$ ATCC $51284=$ CIP 105832) is the type strain of the species Brachyspira murdochii. This strain was first described as Serpulina murdochii [1,2], and later transferred to the genus Brachyspira [3]. The genus Brachyspira consists currently of seven species, with Brachyspira aalborgi as the type species [4,5]. The genus Brachyspira is the only genus in the not yet formally described family 'Brachyspiraceae' [6,7]. The generic name derives from 'brachys', Greek for short, and 'spira', Latin for a coil, a helix, to mean 'a short helix' [5]. The species name for B. murdochii de- rives from the city of Murdoch, in recognition of work conducted at Murdoch University in Western Australia, where the type strain was identified [1]. Some species of the genus Brachyspira cause swine dysentery and porcine intestinal spirochetosis. Swine dysentery is a severe, mucohemorrhagic disease that sometimes leads to death of the animals [1]. B. murdochii is generally not considered to be a pathogen, although occasionally it has been seen in association with colitis in pigs $[3,8]$, and was also associated with clinical problems on certain farms [9-11]. 
In 1992, a user-friendly and robust novel PCR-based restriction fragment length polymorphism analysis of the Brachyspira nox-gene was developed which allows one to identify with high specificity members of $B$. murdochii using only two restriction endonucleases only [12]. More recently, a multi-locus sequence typing scheme was developed that facilitates the identification of Brachyspira species and reveals the intraspecies diversity of B. murdochii [13] (see also http://pubmlst.org/brachyspira/).

Only one genome of a member of the family ' $\mathrm{Bra}$ chyspiraceae' has been sequenced to date: $B$. hyodysenteriae strain WA1 [14]. It is an intestinal pathogen of pigs. Based on 16S rRNA sequence this strain is $0.8 \%$ different from strain $56-150^{\mathrm{T}}$. Here we present a summary classification and a set of features for B. murdochii 56-150' , together with the description of the complete genomic sequencing and annotation.

\section{Classification and features}

Brachyspira species colonize the lower intestinal tract (cecum and colons) of animals and humans [6]. The type of B. murdochii, 56-150', was isolated from a healthy swine in Canada $[1,15]$. Other isolates have been obtained from wild rats in Ohio, USA, from laboratory rats in Murdoch, Western Australia [16], and from the joint fluid of a lame pig [17]. Further isolates have been obtained from the feces or gastrointestinal tract of pigs in Canada, Tasmania, Queensland, and Western Australia $[2,15]$. The type strains of the other species of the genus Brachyspira share 95.9-99.4\% 16S rRNA sequence identity with strain 56-150' . GenBank contains 16S rRNA sequences for about $250 \mathrm{Bra}$ chyspira isolates, all of which share at least $96 \%$ sequence identity with strain $56-150^{\mathrm{T}}$ [18]. The closest related type strain of a species outside of the Brachyspira, but within the order Spirochaetales, is Turneriella parva [19], which exhibits only 75\% 16S rRNA sequence similarity [18]. 16S rRNA sequences from environmental samples and metagenomic surveys do not exceed $78-79 \%$ sequence similarity to strain $56-150^{\mathrm{T}}$, with the sole exception of one clone from a metagenomic analysis of human diarrhea [20], indicating that members of the species, genus and even family are poorly represented in the habitats outside of various animal intestines screened thus far (status March 2010).

Figure 1 shows the phylogenetic neighborhood of B. murdochii $56-150^{\mathrm{T}}$ in a $16 \mathrm{~S}$ rRNA based tree. The sequence of the single 16S rRNA gene in the genome sequence is identical with the previously published 16S rRNA gene sequence generated from DSM 12563 (AY312492).

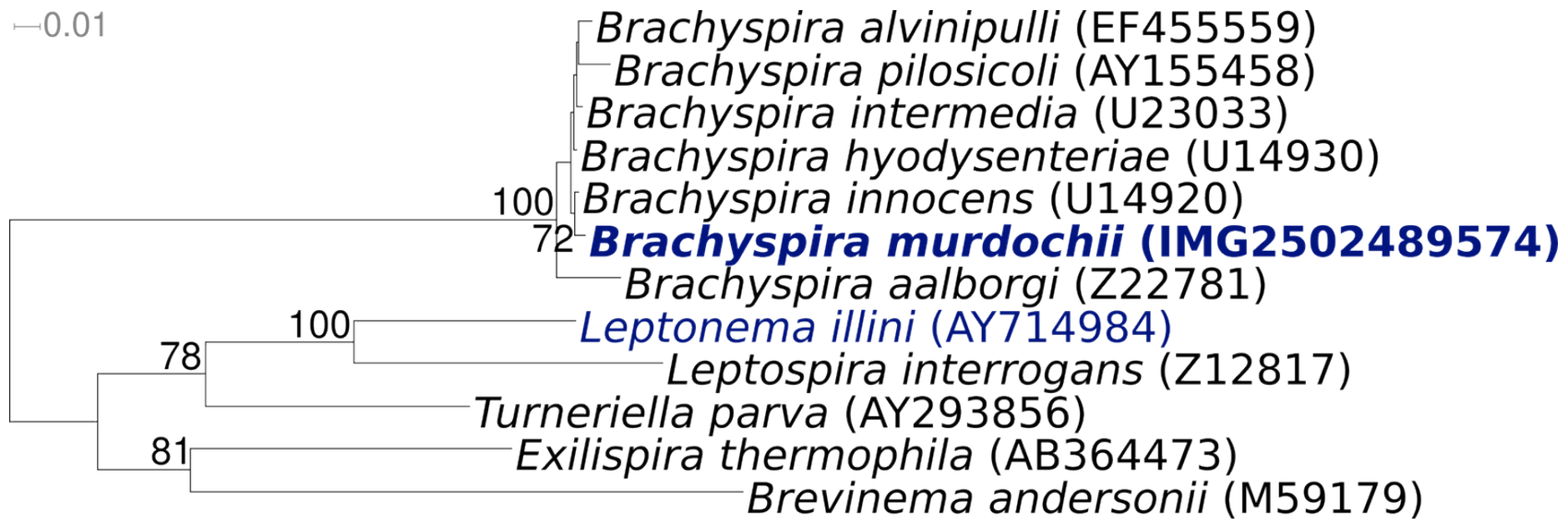

Figure 1. Phylogenetic tree highlighting the position of $B$. murdochii $56-150^{\top}$ relative to the other type strains within the genus and to the type strains of the other genera within the class Spirochaetes (excluding members of the Spirochaetaceae). The tree was inferred from 1,396 aligned characters [21,22] of the 16S rRNA gene sequence under the maximum likelihood criterion [23] and rooted in accordance with the current taxonomy. The branches are scaled in terms of the expected number of substitutions per site. Numbers above branches are support values from 1,000 bootstrap replicates if [24] larger than 60\%. Lineages with type strain genome sequencing projects registered in GOLD [25] are shown in blue, published genomes in bold. 
The cells of $B$. murdochii $56-150^{\mathrm{T}}$ were 5 - 8 by 0.35 - $0.4 \mu \mathrm{m}$ in size (Table 1 and Figure 2), and each cell possessed 22 to 26 flagella (11 to 13 inserted at each end) [1]. In brain/heart infusion broth containing $10 \%$ calf serum (BHIS) under an $\mathrm{N}_{2}-\mathrm{O}_{2}$ (99::l) atmosphere, strain $56-150^{\mathrm{T}}$ had optimum growth temperatures of 39 to $42^{\circ} \mathrm{C}$ (shortest population doubling times and highest final population densities) [1]. In BHIS broth at $39^{\circ} \mathrm{C}$, the doubling times of strain $56-150^{\mathrm{T}}$ were 2 to $4 \mathrm{~h}$, and the final population densities were $0.5 \times 10^{9}$ to $2.0 \times 10^{9}$ cells $/ \mathrm{ml}$. Strain $56-150^{\mathrm{T}}$ did not grow at 32 or $47^{\circ} \mathrm{C}[1]$.

Substrates that support growth of strain $56-150^{\mathrm{T}}$ in HS broth (basal heart infusion broth containing $10 \%$ fetal calf serum) include glucose, fructose, sucrose, N-acetylglucosamine, pyruvate, L-fucose, cellobiose, trehalose, maltose, mannose, and lactose, but not galactose, D-fucose, glucosamine, ribose, raffinose, rhamnose, or xylose [1]. In HS broth supplemented with $0.4 \%$ glucose under an $\mathrm{N}_{2}-\mathrm{O}_{2}$ (99:I) atmosphere, the metabolic end products of strain
$56-150^{\mathrm{T}}$ are acetate, butyrate, ethanol, $\mathrm{CO}_{2}$, and $\mathrm{H}_{2}$. Strain $56-150^{\mathrm{T}}$ produces more $\mathrm{H}_{2}$ than $\mathrm{CO}_{2}$ [1], which is indicative of NADH-ferredoxin oxidoreductase reaction [6]. The ethanol is likely to be formed from acetyl-CoA by the enzymes acetaldehyde dehydrogenase and alcohol dehydrogenase [6]. Strain $56-150^{\mathrm{T}}$ is weakly hemolytic, negative for indole production, does not hydrolyze hippurate, is negative for $\alpha$-galactosidase and $\alpha$ glucosidase activity, but positive for $\beta$-glucosidase activity [1]. Strain $56-150^{\mathrm{T}}$ is anaerobic but aerotolerant [1].

Minimal inhibitory concentrations have been determined for strain 56-150 ${ }^{\mathrm{T}}$ for tiamulin hydrogen fumarate, tylosin tartrate, erythromycin, clindamycin hydrochloride, virginiamycin, and carbadox [36]. Several strains of $B$. murdochii have been described to be naturally resistant against rifampicin $[7,32]$. Also, a ring test for quality assessment for diagnostics and antimicrobial susceptibility testing of the genus Brachyspira has been reported [37].

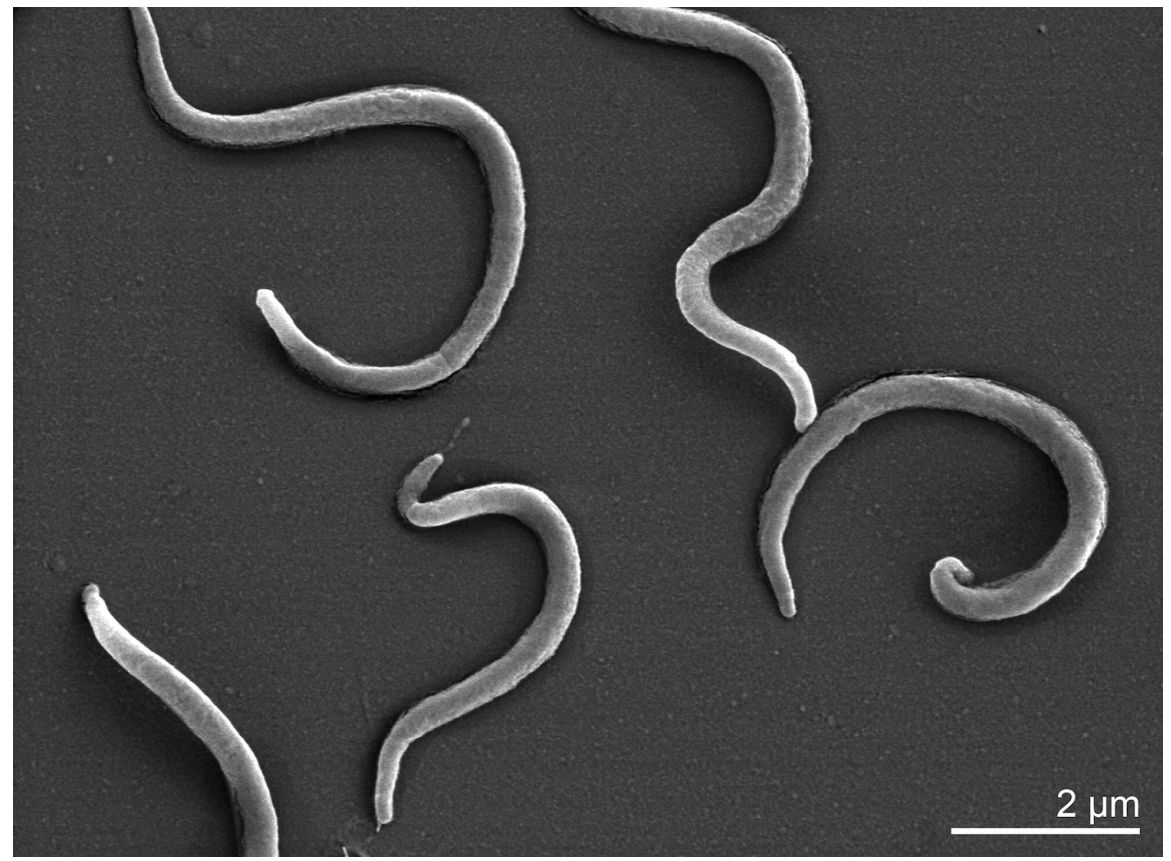

Figure 2. Scanning electron micrograph of B. murdochii $56-150^{\top}$

\section{Chemotaxonomy}

At present, there are no reports on the chemotaxonomy of B. murdochii. However, some data are available for B. innocens (formerly classified as Treponema innocens [6]), the species that is currently most closely related to $B$. murdochii [13]. B. innocens cellular phospholipids and glycolipids were found to contain acyl (fatty acids with ester linkage) with alkenyl (unsaturated alcohol with ether linkage) side chains $[6,38]$. The glycolipid of $B$. innocens contains monoglycosyldiglyceride (MGDG) and, in most strains, acylMGDG is also found, with galactose as the predominant sugar moiety [38]. 
Table 1. Classification and general features of B. murdochii 56-150 according to the MIGS recommendations [26]

\begin{tabular}{|c|c|c|c|}
\hline MIGS ID & Property & Term & Evidence code \\
\hline & \multirow{8}{*}{ Current classification } & Domain Bacteria & TAS [27] \\
\hline & & Phylum Spirochaetes & TAS $[28]$ \\
\hline & & Class Spirochaetes & TAS $[28]$ \\
\hline & & Order Spirochaetales & TAS $[29,30]$ \\
\hline & & Family Brachyspiraceae & TAS [31] \\
\hline & & Genus Brachyspira & TAS [5] \\
\hline & & Species Brachyspira murdochii & TAS [1] \\
\hline & & Type strain 56-150 & TAS [1] \\
\hline & Gram stain & negative & TAS [1] \\
\hline & Cell shape & helical cells with regular coiling pattern & TAS [1] \\
\hline & Motility & motile (periplasmic flagella) & TAS [1] \\
\hline & Sporulation & non-sporulating & TAS [1] \\
\hline & Temperature range & does not grow at $32^{\circ} \mathrm{C}$ or $47^{\circ} \mathrm{C}$ & TAS [1] \\
\hline & Optimum temperature & $39^{\circ} \mathrm{C}$ & TAS [1] \\
\hline & Salinity & unknown & TAS \\
\hline \multirow[t]{3}{*}{ MIGS-22 } & Oxygen requirement & anaerobic, aerotolerant & TAS [1] \\
\hline & Carbon source & soluble sugars & TAS [1] \\
\hline & Energy source & chemoorganotrophic & TAS [1] \\
\hline MIGS-6 & Habitat & animal intestinal tract & TAS [6] \\
\hline MIGS-15 & Biotic relationship & host-associated & TAS [32] \\
\hline \multirow[t]{3}{*}{ MIGS-14 } & Pathogenicity & no & TAS [33] \\
\hline & Biosafety level & 1 & TAS [34] \\
\hline & Isolation & swine & TAS [15] \\
\hline MIGS-4 & Geographic location & Quebec, Canada & TAS [15] \\
\hline MIGS-5 & Sample collection time & 1992 & TAS [15] \\
\hline MIGS-4.1 & Latitude & 52.939 & TAS [1] \\
\hline MIGS-4.2 & Longitude & -73.549 & TAS [1] \\
\hline MIGS-4.3 & Depth & not reported & TAS \\
\hline MIGS-4.4 & Altitude & not reported & TAS \\
\hline
\end{tabular}

Evidence codes - IDA: Inferred from Direct Assay (first time in publication); TAS: Traceable Author Statement (i.e., a direct report exists in the literature); NAS: Non-traceable Author Statement (i.e., not directly observed for the living, isolated sample, but based on a generally accepted property for the species, or anecdotal evidence). These evidence codes are from of the Gene Ontology project [35]. If the evidence code is IDA, then the property was directly observed by one of the authors or an expert mentioned in the acknowledgements.

\section{Genome sequencing and annotation \\ Genome project history}

This organism was selected for sequencing on the basis of its phylogenetic position [39], and is part of the Genomic Encyclopedia of Bacteria and Archaea project [40]. The genome project is deposited in the Genome OnLine Database [25] and the com- plete genome sequence is deposited in GenBank Sequencing, finishing and annotation were performed by the DOE Joint Genome Institute (JGI). A summary of the project information is shown in Table 2. 
Table 2. Genome sequencing project information

\begin{tabular}{lll}
\hline MIGS ID & Property & Term \\
\hline MIGS-31 & Finishing quality & $\begin{array}{l}\text { Finished } \\
\text { Four genomic libraries: two Sanger 6kb } \\
\text { and 8 kb pMCL200 library, one fosmid } \\
\text { library, one 454 standard library }\end{array}$ \\
LIGS-28 & Libraries used & ABI3730, 454 GS FLX \\
MIGS-29 & Sequencing platforms & N.7× Sanger; 48.9× pyrosequence \\
MIGS-30 & Sequencing coverage & Newbler version 1.1.02.15, phrap \\
MIGS-32 & Gene calling method & Prodigal 1.4, GenePRIMP \\
& INSDC ID & CP001959 \\
& Genbank Date of Release & May 13, 2010 \\
& GOLD ID & Gc01276 \\
& NCBI project ID & 29543 \\
& Database: IMG-GEBA & 2502422316 \\
& Source material identifier & DSM 12563 \\
& Project relevance & Tree of Life, GEBA \\
\hline
\end{tabular}

\section{Growth conditions and DNA isolation}

B. murdochii, strain 56-150', DSM 12563, was grown anaerobically in DSMZ medium 840 (Serpulina murdochii medium) [41] at $37^{\circ} \mathrm{C}$. DNA was isolated from 0.5-1 g of cell paste using Qiagen Genomic 500 DNA Kit (Qiagen, Hilden, Germany) with lysis modification st/L according to $\mathrm{Wu}$ et al. [40].

\section{Genome sequencing and assembly}

The genome was sequenced using a combination of Sanger and 454 sequencing platforms. All general aspects of library construction and sequencing performed can be found at the JGI website (http://www.jgi.doe.gov/). In total, 861,386 Pyrosequencing reads were assembled using the Newbler assembler version 1.1.02.15 (Roche). Large Newbler contigs were broken into 3,554 overlapping fragments of $1,000 \mathrm{bp}$ and entered into assembly as pseudo-reads. The sequences were assigned quality scores based on Newbler consensus q-scores with modifications to account for overlap redundancy and adjust inflated qscores. A hybrid 454/Sanger assembly was made using the parallel phrap assembler (High Performance Software, LLC). Possible misassemblies were corrected with Dupfinisher or transposon bombing of bridging clones [42]. A total of 300 Sanger finishing reads were produced to close gaps, to resolve repetitive regions, and to raise the quality of the finished sequence. The error rate of the completed genome sequence is less than 1 in
100,000 . Together, the combination of the Sanger and 454 sequencing platforms provided 68.6× coverage of the genome. The final assembly contains 79,829 Sanger reads and 861,386 pyrosequencing reads.

\section{Genome annotation}

Genes were identified using Prodigal [43] as part of the Oak Ridge National Laboratory genome annotation pipeline, followed by a round of manual curation using the JGI GenePRIMP pipeline [44]. The predicted CDSs were translated and used to search the National Center for Biotechnology Information (NCBI) nonredundant database, UniProt, TIGRFam, Pfam, PRIAM, KEGG, COG, and InterPro databases. Additional gene prediction analysis and functional annotation was performed within the Integrated Microbial Genomes - Expert Review (IMG-ER) platform [45].

\section{Genome properties}

The genome is 3,241,804 bp long and comprises one main circular chromosome with an overall GC content of $27.8 \%$ (Table 3 and Figure 3). Of the 2,893 genes predicted, 2,853 were protein-coding genes, and 40 RNAs. A total of 44 pseudogenes were identified. The majority of the protein-coding genes $(66.2 \%)$ were assigned a putative function while those remaining were annotated as hypothetical proteins. The distribution of genes into COGs functional categories is presented in Table 4. 
Table 3. Genome Statistics

\begin{tabular}{lrr}
\hline Attribute & Value & \% of Total \\
\hline Genome size (bp) & $3,241,804$ & $100.00 \%$ \\
DNA coding region (bp) & $2,841,470$ & $87.65 \%$ \\
DNA G+C content (bp) & 899,647 & $27.75 \%$ \\
Number of replicons & 1 & \\
Extrachromosomal elements & 0 & \\
Total genes & 2,893 & $100.00 \%$ \\
RNA genes & 40 & $1.38 \%$ \\
rRNA operons & 1 & \\
Protein-coding genes & 2,893 & $98.62 \%$ \\
Pseudo genes & 44 & $1.52 \%$ \\
Genes with function prediction & 1,914 & $66.16 \%$ \\
Genes in paralog clusters & 610 & $21.09 \%$ \\
Genes assigned to COGs & 1,815 & $62.74 \%$ \\
Genes assigned Pfam domains & 1,973 & $68.20 \%$ \\
Genes with signal peptides & 577 & $19.94 \%$ \\
Genes with transmembrane helices & 737 & $25.48 \%$ \\
CRISPR repeats & 2 & \\
\hline
\end{tabular}

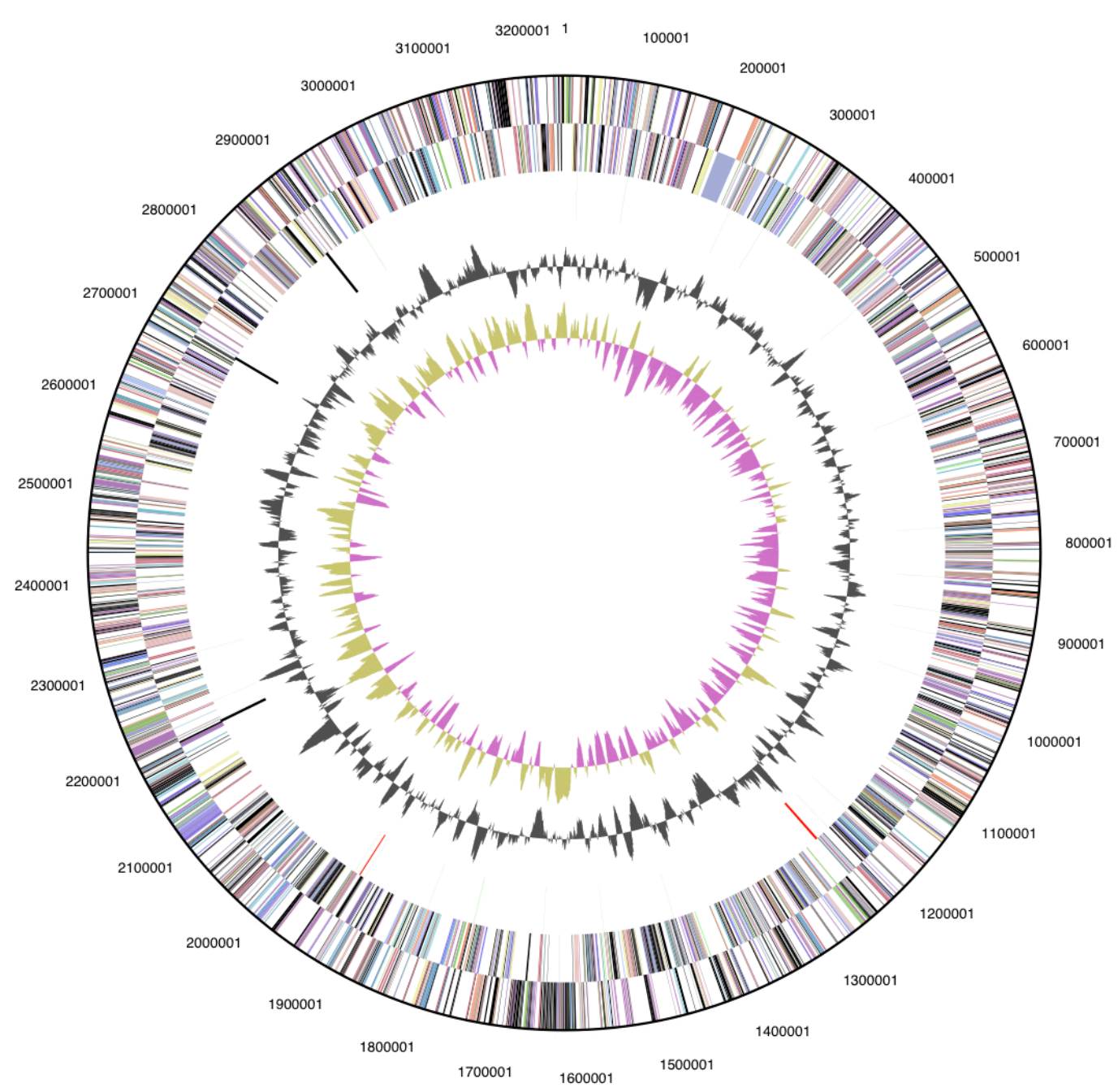

Figure 3. Graphical circular map of the genome. From outside to the center: Genes on forward strand (color by COG categories), Genes on reverse strand (color by COG categories), RNA genes (tRNAs green, rRNAs red, other RNAs black), GC content, GC skew. 
Table 4. Number of genes associated with the general COG functional categories

\begin{tabular}{crrl}
\hline Code & value & \%age & Description \\
\hline J & 134 & 6.6 & Translation, ribosomal structure and biogenesis \\
A & 1 & 0.0 & RNA processing and modification \\
K & 81 & 4.0 & Transcription \\
L & 104 & 5.2 & Replication, recombination and repair \\
B & 0 & 0.0 & Chromatin structure and dynamics \\
D & 20 & 1.0 & Cell cycle control, cell division, chromosome partitioning \\
Y & 0 & 0.0 & Nuclear structure \\
V & 44 & 2.2 & Defense mechanisms \\
T & 116 & 5.8 & Signal transduction mechanisms \\
M & 143 & 7.1 & Cell wall/membrane/envelope biogenesis \\
N & 100 & 5.0 & Cell motility \\
Z & 0 & 0.0 & Cytoskeleton \\
W & 0 & 0.0 & Extracellular structures \\
U & 51 & 2.5 & Intracellular trafficking secretion, and vesicular transport \\
O & 62 & 3.1 & Posttranslational modification, protein turnover, chaperones \\
C & 111 & 5.5 & Energy production and conversion \\
G & 143 & 7.1 & Carbohydrate transport and metabolism \\
E & 185 & 9.2 & Amino acid transport and metabolism \\
F & 56 & 2.8 & Nucleotide transport and metabolism \\
H & 67 & 3.3 & Coenzyme transport and metabolism \\
I & 53 & 2.6 & Lipid transport and metabolism \\
P & 99 & 4.9 & Inorganic ion transport and metabolism \\
Q & 20 & 1.0 & Secondary metabolites biosynthesis, transport and catabolism \\
R & 286 & 14.2 & General function prediction only \\
S & 143 & 7.1 & Function unknown \\
- & 1,078 & 37.3 & Not in COGs \\
\hline & & &
\end{tabular}

\section{Acknowledgements}

We would like to gratefully acknowledge the help of Sabine Welnitz for growing B. murdochii cells and Susanne Schneider for DNA extraction and quality analysis (both at DSMZ). This work was performed under the auspices of the US Department of Energy Office of Science, Biological and Environmental Research Program, and by the University of California, Lawrence Berkeley National Laboratory under con-

\section{References}

1. Stanton TB, Fournie-Amazouz E, Postic D, Trott DJ, Grimont PAD, Baranton G, Hampson DJ, Saint Girons I. Recognition of two new species of intestinal spirochetes: Serpulina intermedia sp. nov. and Serpulina murdochii sp. nov. Int J Syst Bacteriol 1997; 47:1007-1012. PubMed doi:10.1099/00207713-47-4-1007 tract No. DE-AC02-05CH11231, Lawrence Livermore National Laboratory under Contract No. DE-AC5207NA27344, Los Alamos National Laboratory under contract No. DE-AC02-06NA25396, UT-Battelle, and Oak Ridge National Laboratory under contract DEAC05-000R22725, as well as German Research Foundation (DFG) INST 599/1-1 and SI 1352/1-2.
2. Lee JI, Hampson DJ. Genetic characterisation of intestinal spirochaetes and their association with disease. J Med Microbiol 1994; 40:365-371. PubMed doi:10.1099/00222615-40-5-365

3. Hampson DJ, La T. Reclassification of Serpulina intermedia and Serpulina murdochii in the genus Brachyspira as Brachyspira intermedia comb. nov. 
and Brachyspira murdochii comb. nov. Int I Syst Evol Microbiol 2006; 56:1009-1012. PubMed doi:10.1099/ijs.0.64004-0

4. Euzéby JP. List of bacterial names with standing in nomenclature: A folder available on the Internet. Int J Syst Bacteriol 1997; 47:590-592. PubMed doi:10.1099/00207713-47-2-590

5. Hovind-Hougen K, Birch-Andersen A, HenrikNielsen R, Orholm M, Pedersen JO, Teglbjaerg PS, Thaysen EH. Intestinal spirochetosis: morphological characterization and cultivation of the spirochete Brachyspira aalborgi gen. nov., sp. nov. J Clin Microbiol 1982; 16:1127-1136. PubMed

6. Stanton TB. 2006. The genus Brachyspira. In M Dworkin, S Falkow, E Rosenberg, KH Schleifer E Stackebrandt (eds), The Prokaryotes, 3. ed, vol. 7. Springer, New York, p. 330-356.

7. Paster BJ, Dewhirst FE. Phylogenetic foundation of spirochetes. J Mol Microbiol Biotechnol 2000; 2:341-344. PubMed

8. Weissenböck H, Maderner A, Herzog AM, Lussy $\mathrm{H}$, Nowotny $\mathrm{N}$. Amplification and sequencing of Brachyspira spp. specific portions of nox using paraffin-embedded tissue samples from clinical colitis in Austrian pigs shows frequent solitary presence of Brachyspira murdochii. Vet Microbiol 2005; 111:67-75. PubMed doi:10.1016/j.vetmic.2005.09.002

9. Stephens CP, Hampson DJ. Prevalence and disease association of intestinal spirochaetes in chickens in eastern Australia. 1999; 28:447-454.

10. Stephens CP, Oxberry SL, Phillips ND, La T, Hampson DJ. The use of multilocus enzyme electrophoresis to characterise intestinal spirochaetes (Brachyspira spp.) colonising hens in commercial flocks. Vet Microbiol 2005; 107:149-157. PubMed doi:10.1016/j.vetmic.2005.01.011

11. Feberwee A, Hampson DJ, Phillips ND, La T, van der Heijden HMJF, Wellenberg GJ, Dwars RM, Landman WJM. Identification of Brachyspira hyodysenteriae and other pathogenic Brachyspira species in chickens from laying flocks with diarrhea or reduced production or both. J Clin Microbiol 2008; 46:593-600. PubMed doi:10.1128/JCM.01829-07

12. Rohde J, Rothkamp A, Gerlach GF. Differentiation of porcine Brachyspira species by a novel nox PCR-based restriction fragment length polymorphism analysis. J Clin Microbiol 2002; 40:25982600. PubMed doi:10.1128/JCM.40.7.2598$\underline{2600.2002}$
13. Råsbäck $T$, Johansson $K E$, Jansson DS, Fellstrom C, Alikhani MY, La T, Dunn DS, Hampson DJ. Development of a multilocus sequence typing scheme for intestinal spirochaetes within the genus Brachyspira. Microbiology 2007; 153:40744087. PubMed doi:10.1099/mic.0.2007/008540$\underline{0}$

14. Bellgard MI, Eanchanthuek P, La T, Ryan K, Moolhuijzen P, Albertyn Z, Shaban B, Motro Y, Dunn DS, Schibeci D, et al. Genome sequence of the pathogenic intestinal spirochaete Brachyspira hyodysenteriae reveals adapations to its lifestyle in the porcine large intestions. PLOS ONE 2009; 4:e4641. PubMed doi:10.1371/journal.pone.0004641

15. Lee JI, Hampson DJ, Lymbery AJ, Harders SJ. The porcine intestinal spirochaetes: identification of new genetic groups. Vet Microbiol 1993; 34:273285. PubMed doi:10.1016/0378-1135(93)90017$\underline{2}$

16. Trott DJ, Atyeo RF, Lee JI, Swayne DA, Stoutenbgurg JW, Hampson DJ. Genetic relatedness amongst intestinal spirochaetes isolated from rate and birds. Lett Appl Microbiol 1996; 23:431-436. PubMed doi:10.1111/j.1472765X.1996.tb01352.x

17. Hampson DJ, Robertson ID, Oxberry SL. Isolation of Serpulina murdochii from the joint fluid of a lame pig. Aust Vet J 1999; 77:48. $\underline{\text { PubMed }}$ doi:10.1111/j.1751-0813.1999.tb12430.x

18. Chun J, Lee JH, Jung Y, Kim M, Kim S, Kim BK, Lim YW. EzTaxon: a web-based tool for the identification of prokaryotes based on 16S ribosomal RNA gene sequences. Int / Syst Evol Microbiol 2007; 57:2259-2261. PubMed doi:10.1099/ijs.0.64915-0

19. Levett PN, Morey RE, Galloway R, Steigerwalt AG, Ellis WA. Reclassification of Leptospira parva Hovind-Hougen et al. 1982 as Turneriella parva gen. nov., comb. nov. Int I Syst Evol Microbiol 2005; 55:1497-1499. PubMed doi:10.1099/ijs.0.63088-0

20. Finkbeiner SR, Allred AF, Tarr PI, Klenin EJ, Kirkwood CD, Wang D. Metagenomic analysis of human iarrhea: viral detection and discovery. PLoS Pathog 2008; 4:e1000011. PubMed doi:10.1371/journal.ppat.1000011

21. Castresana J. Selection of conserved blocks from multiple alignments for their use in phylogenetic analysis. Mol Biol Evol 2000; 17:540-552. $\underline{\text { PubMed }}$ 
22. Lee C, Grasso C, Sharlow MF. Multiple sequence alignment using partial order graphs. BioinformatiCs 2002; 18:452-464. PubMed doi:10.1093/bioinformatics/18.3.452

23. Stamatakis A, Hoover P, Rougemont J. A Rapid Bootstrap algorithm for the RAxML web servers. Syst Biol 2008; 57:758-771. PubMed doi:10.1080/10635150802429642

24. Pattengale ND, Alipour M, Bininda-Emonds ORP, Moret BME, Stamatakis A. How many bootstrap replicates are necessary? Lect Notes Comput Sci 2009; 5541:184-200. doi:10.1007/978-3-64202008-7_13

25. Liolios K, Chen IM, Mavromatis K, Tavernarakis N, Hugenholtz P, Markowitz VM, Kyrpides NC. The Genomes On Line Database (GOLD) in 2009: status of genomic and metagenomic projects and their associated metadata. Nucleic Acids Res 2010; 38:D346-D354. PubMed doi:10.1093/nar/gkp848

26. Field D, Garrity G, Gray T, Morrison N, Selengut J, Sterk P, Tatusova T, Thomson N, Allen MJ, Angiuoli SV, et al. The minimum information about a genome sequence (MIGS) specification. Nat Biotechnol 2008; 26:541-547. PubMed doi:10.1038/nbt1360

27. Woese CR, Kandler O, Wheelis ML. Towards a natural system of organisms: proposal for the domains Archaea, Bacteria, and Eucarya. Proc Natl Acad Sci USA 1990; 87:4576-4579. $\underline{\text { PubMed }}$ doi:10.1073/pnas.87.12.4576

28. Garrity GM, Lilburn TG, Cole JR, Harrison SH, Euzéby J, Tindall BJ. Taxonomic outline of the Bacteria and Archaea, Release 7.7 March 6, 2007. Part 11 - The Bacteria: Phyla "Planctomycetes", "Chlamydiae", "Spirochaetes", "Fibrobacteres", "Acidobacteria", "Bacteroidetes", "Fusobacteria", "Verrucomicrobia", "Dictyoglomi", "Gemmatimonadetes", and "Lentisphaerae". http://www.taxonomicoutline.org/index.php/toba /article/viewFile/188/220 2007.

29. Skerman VBD, McGowan V, Sneath PHA. Approved Lists of Bacterial Names. Int J Syst Bacteriol 1980; 30:225-420. doi:10.1099/00207713$\underline{30-1-225}$

30. Buchanan RE. Studies in the nomenclature and classification of Bacteria. II. The primary subdivisions of the Schizomycetes. I Bacteriol 1917; 2:155-164. PubMed

31. Paster BJ, Dewhirst FE. Phylogenetic foundation of spirochetes. J Mol Microbiol Biotechnol 2000; 2:341-344. PubMed
32. Imachi H, Sakai S, Hirayama H, Nakagawa $\mathrm{S}$, Nunoura T, Takai K, Horikoshi K. Exilispira thermophila gen. nov., sp. nov., an anaerobic, thermophilic spirochaete isolated from a deep-sea hydrothermal vent chimney. Int I Syst Evol Microbiol 2008; 58:2258-2265. PubMed doi:10.1099/ijs.0.65727-0

33. Stanton TB, Postic D, Jensen NS. Serpulina alvinipulli sp. nov., a new Serpulina species that is enteropathogenic for chickens. Int I Syst Bacteriol 1998; 48:669-676. PubMed doi:10.1099/00207713-48-3-669

34. Classification of Bacteria and Archaea in risk groups. www.baua.de TRBA 466.

35. Ashburner M, Ball CA, Blake JA, Botstein D, Butler $\mathrm{H}$, Cherry JM, Davis AP, Dolinski K, Dwight SS, Eppig JT, et al. Gene Ontology: tool for the unification of biology. Nat Genet 2000; 25:25-29. $\underline{\text { PubMed doi: } 10.1038 / 75556}$

36. Karlsson M, Fellstrom C, Gunnarsson A, Landen A, Franklin A. Antimicrobial susceptibility testing of porcine brachyspira (Serpulina) species isolates. J Clin Microbiol 2003; 41:2596-2604. PubMed doi:10.1128/JCM.41.6.2596-2604.2003

37. Råsbäck T, Fellström C, Bergsjø B, Cizek A, Collin K, Gunnarsson A, Jensen SM, Mars A, Thomson J, $V y t P$, et al. Assessment of diagnostics and antimicrobial susceptibility testing of Brachyspira species using a ring test. Vet Microbiol 2005; 109:229-243. PubMed doi:10.1016/j.vetmic.2005.05.009

38. Matthews HM, Kinyon JM. Cellular lipid comparisons between strains of Treponema hyodysenteriae and Treponema innocens. Int I Syst Bacteriol 1984; 34:160-165. doi:10.1099/00207713-34-2$\underline{160}$

39. Klenk HP, Göker M. En route to a genome-based classification of Archaea and Bacteria? Syst Appl Microbiol (In press).

40. Wu D, Hugenholtz P, Mavromatis K, Pukall R, Dalin E, Ivanova NN, Kunin V, Goodwin L, Wu $M$, Tindall BJ, et al. A phylogeny-driven genomic encyclopaedia of Bacteria and Archaea. Nature 2009; 462:1056-1060. PubMed doi:10.1038/nature08656

41. List of growth media used at DSMZ: http://www.dsmz.de/microorganisms/media list.p hp

42. Sims D, Brettin T, Detter J, Han C, Lapidus A, Copeland A, Glavina Del Rio T, Nolan M, Chen F, Lucas $S$, et al. Complete genome sequence of $\mathrm{Ky}$ - 
tococcus sedentarius type strain $\left(541^{\top}\right)$. Stand

Genomic Sci 2009; 1:12-20. doi:10.4056/sigs.761

43. Hyatt $\mathrm{D}$, Chen GL, Locascio PF, Land ML, Larimer FW, Hauser LJ. Prodigal Prokaryotic Dynamic Programming Genefinding Algorithm. BMC Bioinformatics 2010; 11:119. PubMed doi:10.1186/1471-2105-11-119

44. Pati A, Ivanova N, Mikhailova N, Ovchinikova G, Hooper SD, Lykidis A, Kyrpides NC. GenePRIMP:
A Gene Prediction Improvement Pipeline for microbial genomes. Nat Methods (Epub).

doi:10.1038/nmeth.1457

45. Markowitz VM, Ivanova NN, Chen IMA, Chu K, Kyrpides NC. IMG ER: a system for microbial genome annotation expert review and curation. Bioinformatics 2009; 25:2271-2278. PubMed

doi:10.1093/bioinformatics/btp393 